\title{
Incidental Findings on Magnetic Resonance Imaging of the Spine in the Asymptomatic Pediatric Population: A Systematic Review
}

\author{
Uma Ramadorai ${ }^{1}$ Justin Hire ${ }^{1}$ John G. DeVine ${ }^{2}$ \\ ${ }^{1}$ Department of Orthopaedics and Rehabilitation, Dwight D. \\ Eisenhower Army Medical Center, Fort Gordon, Georgia, \\ United States \\ ${ }^{2}$ Department of Orthopaedic Surgery, Georgia Regents University, \\ Augusta, Georgia, United States \\ 3 Spectrum Research, Inc., Tacoma, Washington, United States \\ Evid Based Spine Care J 2014;5:95-100.
}

Erika D. Brodt ${ }^{3}$ Joseph R. Dettori ${ }^{3}$

\begin{abstract}
Keywords

- pediatrics

- incidental findings

- magnetic resonance imaging

- asymptomatic

Study Design Systematic review.

Clinical Question What is the prevalence of incidental magnetic resonance imaging (MRI) findings of the spine in asymptomatic pediatric patients?

Methods Electronic databases and reference lists of key articles were searched up to December 15, 2013, to identify studies reporting the incidence or prevalence of incidental findings on MRI in asymptomatic pediatric patients. Athletes or children with a known history of trauma, infection, or congenital abnormalities were excluded. Results Seven publications, one prospective cohort, and six cross-sectional studies met the inclusion criteria. The most commonly reported findings on MRI were discrelated and included degenerative disc disease (seven studies, prevalence 19.6\%), disc herniation/protrusion (four studies, 2.9\%), disc height/narrowed disc space (two studies, 33.7\%), and endplate changes (two studies, 5.3\%). Other disc-related findings, reported by one study each, included bulging disc, abnormal nucleus shape, annular tear, high intensity zone, and nerve root compression, with prevalences ranging from 4.5 to $51.6 \%$. Spondylolisthesis and spondylolysis were reported by one study each with a prevalence of 2.3 and $0 \%$, respectively. Other findings reported included tumors and infections (one study, $0 \%$ for both) and Scheuermann-type changes (one study, 7.7\%). Conclusions The prevalence of positive MRI findings in the asymptomatic pediatric population is higher than previously assumed, particularly in regard to disc morphology, highlighting the importance of correlating the history and physical examination to the MRI findings to avoid misdiagnosis or over-treatment in the pediatric population.
\end{abstract}

\author{
Address for correspondence John G. DeVine, MD, Department of \\ Orthopaedic Surgery, Georgia Regents University, 1120 15th Street, \\ Augusta, GA 30912, United States (e-mail: JDEVINE@gru.edu).
}

\section{Study Rationale and Context}

Magnetic resonance imaging (MRI) is a useful tool to evaluate the spine in the pediatric patient presenting with pain, neurologic findings, trauma, and scoliosis. In the adult popu-

received

March 4, 2014

accepted after revision

June 3, 2014 lation, incidental findings on MRI of the spine in the asymptomatic patient are well documented, demonstrating the high sensitivity of this imaging modality. This phenomenon is likely present in the pediatric population, but the incidence (c) 2014 Georg Thieme Verlag KG Stuttgart · New York
DOI http://dx.doi.org/ 10.1055/s-0034-1386753. ISSN 1663-7976. 
or prevalence of incidental findings has not been as thoroughly investigated.

\section{Clinical Question}

What is the prevalence of incidental MRI findings of the spine in asymptomatic pediatric patients?

\section{Materials and Methods}

Study design: Systematic review.

Search: The databases included PubMed, Cochrane collaboration database, and National Guideline Clearinghouse databases; bibliographies of key articles.

Dates searched: The data were searched from January 1980 to December 15, 2013.

Inclusion criteria: (1) Pediatrics (age $\leq 18$ years); (2) asymptomatic at time of initial assessment (baseline); and (3) findings on MRI of the spine.

Exclusion criteria: (1) Adults; (2) athletes; (3) known history of trauma, infection or congenital abnormalities; (4) findings on radiograph, computed tomography (CT), ultrasound, myelography, or other diagnostic modalities other than MRI; and (5) case reports.

Measure of occurrence: Prevalence.

Outcomes: Incidental MRI findings of the spine.

Analysis: Descriptive statistics. Risk proportions (i.e., prevalence) from individual studies were pooled together when possible to obtain a combined risk estimate/prevalence along with their 95\% confidence intervals (CIs). When zero events were reported by all studies for an outcome, the $\mathrm{CI}$ was found using the "rule of three" estimation. ${ }^{1}$ This method approximates the upper bound of the $95 \% \mathrm{Cl}$ as $3 / \mathrm{n}$. Outcomes included are as reported by the authors, with the exception of signal intensity in one study ${ }^{2}$ and abnormal disc in a second study ${ }^{3}$; these findings were determined to be indicative of degenerative disc disease and were included in that outcome category.

Details about methods can be found in the online supplementary material.

\section{Results}

- Seven publications were identified, one prospective cohort and six cross-sectional studies, which met the inclusion criteria and form the basis for this report (-Fig. 1). A list of excluded studies can be found in the online supplementary material.

- Mean ages of the populations ranged from 8 to 16.3 years (mean age was unable to be determined in one study ${ }^{4}$ (-Table 1).

\section{Disc-Related Findings}

- Degenerative disc disease was reported by all seven studies $(N=557)$ with an overall prevalence of $19.6 \%(95 \% \mathrm{CI}$ : $16.5 \%, 23.1 \%)^{2-8}$

- Disc herniation/protrusion was reported in $2.9 \%$ (1.7\%, $5.0 \%$ ) of the 418 children from four studies. $2,5,6,8$

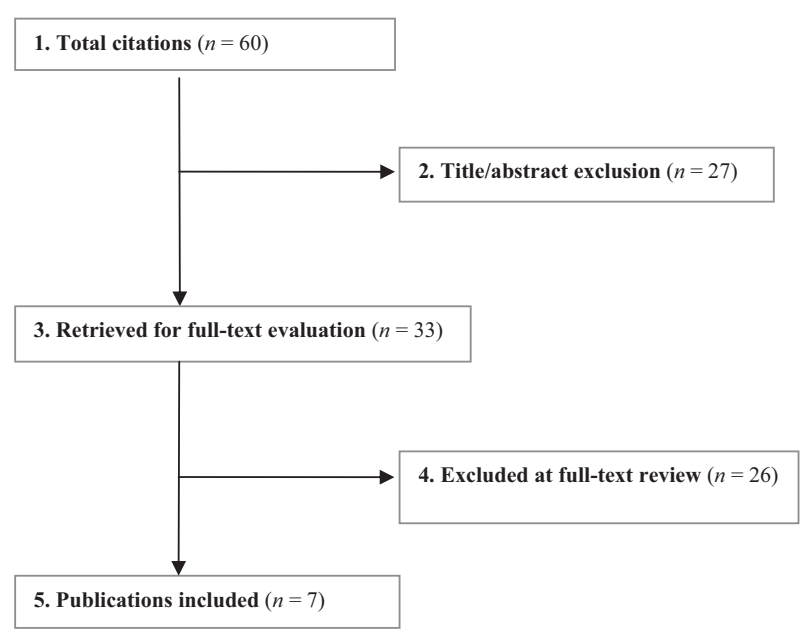

Fig. 1 Flow chart showing results of the literature search.

- The prevalence of disc height reduction/narrowed disc space was $33.7 \%$ (29.1\%, 38.6\%) as reported by two studies $(N=380)^{2,8}$

- Endplate changes were reported by two studies that included a total of 357 children with an overall prevalence of $5.3 \%(3.4 \%, 8.2 \%) ., 5$

- Several other findings (bulging disc, abnormal nucleus shape, annular tear, high intensity zone, and nerve root compression) were reported by one study each with prevalences ranging from 4.5 to $51.6 \%$ (-Table 2 ). ${ }^{2,6}$

\section{Spondylolisthesis/Spondylolysis}

- A low prevalence of both spondylolisthesis and spondylolysis were reported by Kjaer et al and Maurer et al, respectively: $2.3 \%(1.2 \%, 4.6 \%)^{2}$ and $0 \%(0 \%, 13.6 \%)$ (-Table 2). ${ }^{6}$

\section{Other Findings}

- Salo et al reported no tumors or infections among the 49 children included. ${ }^{7}$

- Scheuermann-type changes were reported by Tertti et al $(N=39)$ with a prevalence of $7.7 \%(2.7 \%, 20.3 \%)$ (-Table 2). ${ }^{8}$

\section{Clinical Guidelines}

No clinical guidelines were found.

\section{Illustrative Case}

A 16-year-old man presented to his primary care practitioner with complaints of right-sided posterior hip pain. No significant abnormalities were found on plain imaging to include hip and lumbar/thoracic spine films. A rheumatology consultation was obtained in addition to advanced imaging of the thoracic and lumbar spine. Thoracic MRI revealed multiple Schmorl's nodules as well as a small disc herniation at T7-8 (-Fig. 2). Lumbar spine MRI was within normal limits. 
Table 1 Demographics and characteristic of included studies

\begin{tabular}{|c|c|c|c|}
\hline Author $(y)$ & Study design & Demographics $^{a}$ & MRI findings reported \\
\hline Kjaer et al (2005) & $\begin{array}{l}\text { Cross-sectional } \\
\text { (population-based) }^{\mathrm{b}}\end{array}$ & $\begin{array}{l}N=341 \text { (discs NR) } \\
\text { Mean age: } 13.1 \mathrm{y} \\
\text { (range, } 12-14 \text { ) } \\
\text { Male: NR }\end{array}$ & $\begin{array}{l}\text { - Disc degeneration (i.e., signal intensity): } \\
\text { 18.8\% (64/341) } \\
\text { - Disc herniation: 2.9\% (10/341) } \\
\text { - Disc height: } 37.2 \%(127 / 341) \\
\text { - Abnormal nucleus shape: } 51.6 \%(176 / 341) \\
\text { - Annular tear: } 8.2 \%(28 / 341) \\
\text { - High intensity zone: } 5.3 \%(18 / 341) \\
\text { - Nerve root compression: } 9.1 \%(31 / 341) \\
\text { - Endplate changes: } 5.3 \%(18 / 341) \\
\text { - Spondylolisthesis: } 2.3 \%(8 / 341)\end{array}$ \\
\hline Kujala et al (1996) & $\begin{array}{l}\text { Prospective cohort } \\
\text { (cross-sectional }^{\text {at baseline) }}\end{array}$ & $\begin{array}{l}N=16(\text { disc } N R) \\
\text { Mean age: } 11.9 y \\
\text { (range, } 11.3-12.8) \\
\text { Female: } 100 \%\end{array}$ & $\begin{array}{l}\text { - Disc degeneration: } 12.5 \%(2 / 16) \\
\text { - Disc protrusion/prolapse: } 6.3 \%(1 / 16) \\
\text { - Vertebral endplate changes: } 6.3 \%(1 / 16)\end{array}$ \\
\hline Maurer et al (2011) & Cross-sectional $^{d}$ & $\begin{array}{l}N=22(\text { discs } N R) \\
\text { Mean age: } 16.3 \pm 1.3 y \\
\text { Male: } 100 \%\end{array}$ & $\begin{array}{l}\text { - Disc degeneration: } 9.1 \%(2 / 22) \\
\text { - Herniated disc: } 0 \%(0 / 22) \\
\text { - Bulging disc: } 4.5 \%(1 / 22) \\
\text { - Stress reaction: } 0 \%(0 / 22) \\
\text { - Spondylolysis: } 0 \%(0 / 22)\end{array}$ \\
\hline Paajanen et al (1997) & Cross-sectional $^{\mathrm{e}}$ & $\begin{array}{l}N=80 \text { (395 discs) } \\
\text { age } 10-14 \mathrm{y}: \\
n=10 \text { (50 discs) } \\
\text { age } 15-19 \mathrm{y}: \\
n=70 \text { (345 discs) } \\
\text { Mean age: NR } \\
\text { (range, } 10-19 \mathrm{y}) \\
\text { Male: NR }\end{array}$ & - Disc degeneration: 23.8\% (19/80) \\
\hline Salo et al (1995) & Cross-sectional $^{f}$ & $\begin{array}{l}N=49(245 \text { discs }) \\
\text { Mean age: } 8 \text { y } \\
\text { (range, } 0-14) \\
\text { Male: } N R\end{array}$ & $\begin{array}{l}\text { - Disc degeneration: } 22.4 \%(11 / 49) \\
\text { - Tumor: } 0 \%(0 / 49) \\
\text { - Infection: } 0 \%(0 / 49) \\
\text { - Bone anomaly: } 10.2 \%(5 / 49)\end{array}$ \\
\hline Tertti et al (1990) & Cross-sectional $^{f}$ & $\begin{array}{l}N=10(\text { discs NR) } \\
\text { Mean age: } 12 \pm 2.5 \text { y } \\
\text { (range, } 8-14) \\
\text { Male: NR }\end{array}$ & $\begin{array}{l}\text { - Disc degeneration } \\
\quad \text { (i.e., abnormal disc): } 10 \%(1 / 10)\end{array}$ \\
\hline Tertti et al(1991) & Cross-sectional $^{\mathrm{h}}$ & $\begin{array}{l}N=39(190 \text { discs }) \\
\text { Mean age: } 15 \text { y } \\
\text { Male: NR }\end{array}$ & $\begin{array}{l}\text { - Disc degeneration: } 25.6 \%(10 / 39) \\
\text { - Disc protrusion: } 2.6 \%(1 / 39) \\
\text { - Narrowed disc space: } 2.6 \%(1 / 39) \\
\text { - Scheuermann-type changes: } 7.7 \%(3 / 39) \\
\text { - Transitional vertebra: } 2.6 \%(1 / 39)\end{array}$ \\
\hline
\end{tabular}

Abbreviation: MRI, magnetic resonance imaging.

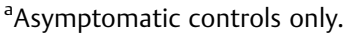

'Study population included a total 439 children (98 symptomatic/LBP, 341 asymptomatic).

'Study population included a total of 98 adolescents: 65 athletes (34 boys, 31 girls) and 33 age-matched nonathletes (16 boys, 17 girls). All children were asymptomatic at presentation/baseline. All the girls were included in MRI studies and complete MRI was available for 43 girls (27 athletes and 16 nonathletes).

${ }^{\mathrm{d}}$ Study population included a total of 44 asymptomatic boys: 22 competitive rowers and 22 age-, weight-, and height-matched nonathletes (i.e., did not practice any regular physical activity (more than once a week).

${ }^{\mathrm{e}} \mathrm{A}$ total 423 patients (age range 10-49) were included in the study: 207 with low-back pain and 216 asymptomatic controls. Only asymptomatic patients aged $\leq 19$ years are included in the analysis $(n=80)$.

${ }^{\mathrm{f}} \mathrm{A}$ total of 81 children were included in the study: 32 symptomatic (LBP) patients and 49 age-matched, asymptomatic controls (healthy volunteers). A total of 45 children were included: 35 gymnasts with or without low back pain and 10 asymptomatic, nonathletes serving as controls (i.e., without any regular sport activities and without history of low back pain).

${ }^{9} \mathrm{MRI}$ was performed approximately 1 year after data collection.

${ }^{h}$ A total of 78 children were included: 39 symptomatic (LBP) and 39 asymptomatic sex-, age-, and school class-matched children serving as controls. 
Table 2 Summary of MRI findings in asymptomatic pediatric subjects

\begin{tabular}{|c|c|c|c|c|}
\hline MRI finding & No. studies & Total events $(n)$ & Total subjects $(N)$ & Prevalence, \% (95\% Cl) \\
\hline \multicolumn{5}{|l|}{ Disc-related } \\
\hline Degenerative disc disease $^{a}$ & 7 & 109 & 557 & $19.6 \%(16.5 \%, 23.1 \%)$ \\
\hline Disc herniation/protrusion & 4 & 12 & 418 & $2.9 \%(1.7 \%, 5.0 \%)$ \\
\hline Disc height/narrowed disc space & 2 & 128 & 380 & $33.7 \%(29.1 \%, 38.6 \%)$ \\
\hline Endplate changes & 2 & 19 & 357 & $5.3 \%(3.4 \%, 8.2 \%)$ \\
\hline Bulging disc & 1 & 1 & 22 & $4.5 \%(0.9 \%, 21.8 \%)$ \\
\hline Nucleus shape & 1 & 176 & 341 & $51.6 \%(46.3 \%, 56.9 \%)$ \\
\hline Annular tear & 1 & 28 & 341 & $8.2 \%(5.7 \%, 11.6 \%)$ \\
\hline High intensity zone & 1 & 18 & 341 & $5.3 \%(3.4 \%, 8.2 \%)$ \\
\hline Nerve root compression & 1 & 31 & 341 & $9.1 \%(6.5 \%, 12.6 \%)$ \\
\hline \multicolumn{5}{|l|}{ Spondylolisthesis/spondylolysis } \\
\hline Spondylolisthesis & 1 & 8 & 341 & $2.3 \%(1.2 \%, 4.6 \%)$ \\
\hline Spondylolysis & 1 & 0 & 22 & $0 \%(0 \%, 13.6 \%)$ \\
\hline \multicolumn{5}{|l|}{ Other } \\
\hline Tumor & 1 & 0 & 49 & $0 \%(0 \%, 6.1 \%)$ \\
\hline Infection & 1 & 0 & 49 & $0 \%(0 \%, 6.1 \%)$ \\
\hline Scheuermann-type changes & 1 & 3 & 39 & $7.7 \%(2.7 \%, 20.3 \%)$ \\
\hline Bone anomalies & 1 & 5 & 49 & $10.2 \%(4.4 \%, 21.8 \%)$ \\
\hline Transitional vertebra & 1 & 1 & 39 & $2.6 \%(0.5 \%, 13.2 \%)$ \\
\hline
\end{tabular}

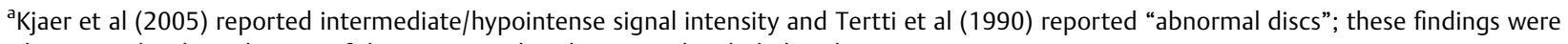
determined to be indicative of degenerative disc disease and included in this category.

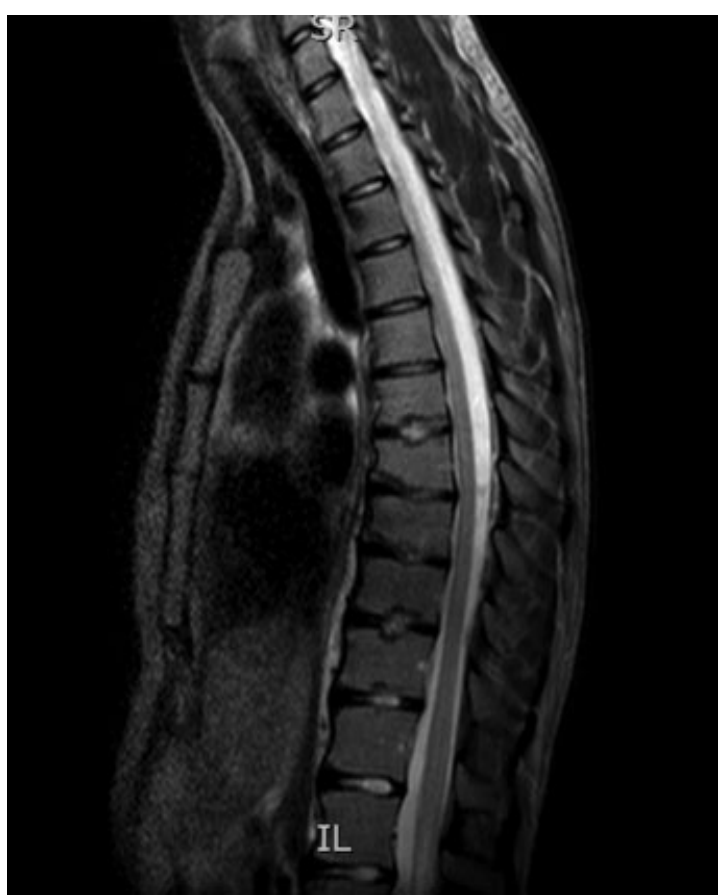

Fig. 2 Thoracic magnetic resonance imaging revealing multiple Schmorl's nodules and small disc herniation at T7-8.

\section{Discussion}

- Strengths

- The question was reviewed systematically. - Asymptomatic control groups were found.

- Limitations

- The asymptomatic control groups were comprised convenience samples (as opposed to random samples) matched to primarily symptomatic children and may not be representative of the general pediatric population.

- Most MRI findings were reported by single studies making the risk estimate (i.e., prevalence) imprecise.

- In the adult population, several studies have established that there are age-dependent disc and osseoligamentous findings on MRI despite a lack of clinical correlation to patient complaints and physical examination findings. Boden et al performed lumbar MRI on 67 asymptomatic adult subjects and found disc herniations in $37 \%$ over the age of $60 .{ }^{9}$ Jensen et al performed MRI of the lumbar spine on 98 adult patients and found abnormal disc appearance in $64 \%{ }^{10}$

- The pediatric population demonstrates a lower rate of incidental findings on MRI compared with the adult population. Our results revealed a prevalence of degenerative disc findings of $19 \%$, disc herniation of $2.9 \%$, narrowed disc space of $33.7 \%$, and endplate changes of $5.3 \%$. 
These incidental findings are not likely a result of physiologic aging given the younger age of the pediatric population.

- It is interesting to note the low prevalence of spondylolysis and spondylolisthesis detected on MRI in the asymptomatic pediatric patient (-Table 2). Although spondylolysis is rarely reported in infants, the prevalence in children older than 6 years of age is similar to that of the adult population of $6 \% .^{11,12}$ In the symptomatic pediatric patient with an acute spondylolysis, single-photon emission CT (SPECT) is sensitive and specific for determining the presence and location of increased bone activity. MRI can approach the sensitivity of SPECT for identifying acute spondylolysis, which is typically accompanied by high signal changes in the adjacent osseous structures. ${ }^{13}$ However, the absence of osseous edema and high signal change makes the MRI less sensitive, and like the SPECT, may be normal appearing in asymptomatic pediatric patients with spondylolysis.

- While not as common as seen in the adult population, positive MRI findings in the pediatric population may be incidental in nature and not related to the presenting complaints of back or leg pain.

- Future research is warranted regarding the prevalence of spine abnormalities in the pediatric population. A larger number of subjects across a heterogeneous population would more accurately reflect the true prevalence of incidental findings on MRI of the spine. In addition, longitudinal studies tracking the fate of the abnormalities as well as the presence or absence of symptoms correlating with those abnormalities could potentially lead to prognostic criteria.

\section{Summary and Conclusion}

MRI is a valuable imaging modality for the evaluation of the patient with suspected spinal pathology. However, the sensitivity of MRI results in a high prevalence of positive findings in asymptomatic adult patients, often referred to as "age-related" physiologic findings because of the absence of correlating back or leg symptoms. The prevalence of positive MRI findings in the asymptomatic pediatric population is higher than previously assumed, particularly in regard to disc morphology, highlighting the importance of correlating the history and physical examination to the MRI findings to avoid misdiagnosis or over-treatment in the pediatric population.
Acknowledgments

Analytic support for this work was provided by Spectrum Research, Inc. with funding from AOSpine.

\author{
Disclosures \\ Uma Ramadorai, none \\ Justin Hire, none \\ John G. DeVine, none \\ Erika D. Brodt, none \\ Joseph R. Dettori, none
}

\section{References}

1 Eypasch E, Lefering R, Kum CK, Troidl H. Probability of adverse events that have not yet occurred: a statistical reminder. BMJ 1995;311(7005):619-620

2 Kjaer P, Leboeuf-Yde C, Sorensen JS, Bendix T. An epidemiologic study of MRI and low back pain in 13-year-old children. Spine (Phila Pa 1976) 2005;30(7):798-806

3 Tertti M, Paajanen H, Kujala UM, Alanen A, Salmi TT, Kormano M. Disc degeneration in young gymnasts. A magnetic resonance imaging study. Am J Sports Med 1990;18(2):206-208

4 Paajanen H, Erkintalo M, Parkkola R, Salminen J, Kormano M. Agedependent correlation of low-back pain and lumbar disc regeneration. Arch Orthop Trauma Surg 1997;116(1-2):106-107

5 Kujala UM, Taimela S, Erkintalo M, Salminen JJ, Kaprio J. Low-back pain in adolescent athletes. Med Sci Sports Exerc 1996;28(2):165-170

6 Maurer M, Soder RB, Baldisserotto M. Spine abnormalities depicted by magnetic resonance imaging in adolescent rowers. Am J Sports Med 2011;39(2):392-397

7 Salo S, Paajanen H, Alanen A. Disc degeneration of pediatric patients in lumbar MRI. Pediatr Radiol 1995;25(3):186-189

8 Tertti MO, Salminen JJ, Paajanen HE, Terho PH, Kormano MJ. Lowback pain and disk degeneration in children: a case-control MR imaging study. Radiology 1991;180(2):503-507

9 Boden SD, Davis DO, Dina TS, Patronas NJ, Wiesel SW. Abnormal magnetic-resonance scans of the lumbar spine in asymptomatic subjects. A prospective investigation. J Bone Joint Surg Am 1990; 72(3):403-408

10 Jensen MC, Kelly AP, Brant-Zawadzki MN. MRI of degenerative disease of the lumbar spine. Magn Reson Q 1994;10(3):173-190

11 Fredrickson BE, Baker D, McHolick WJ, Yuan HA, Lubicky JP. The natural history of spondylolysis and spondylolisthesis. J Bone Joint Surg Am 1984;66(5):699-707

12 Turner RH, Bianco AJ Jr. Spondylolysis and spondylolisthesis in children and teen-agers. J Bone Joint Surg Am 1971;53(7):1298-1306

13 Hollenberg GM, Beattie PF, Meyers SP, Weinberg EP, Adams MJ. Stress reactions of the lumbar pars interarticularis: the development of a new MRI classification system. Spine (Phila Pa 1976) 2002;27(2):181-186 


\section{Editorial Perspective}

EBSJ and its reviewers congratulated the authors on their study idea and execution. The pooled data presented will hopefully form a helpful reference mark for future publications and also serve as a reference for calculations on symptomatic disc degeneration in adult cohorts. EBSJ reviewers wanted to make sure that the present study does not support the contention that "There is a genetic basis to disc degeneration." For many providers, the findings of disc degeneration on MRI in children are alarming, when it should not be. This systematic review by Ramadorai et al does show that intervertebral disc degenerative changes are common even in the asymptomatic pediatric population. This finding will hopefully provide reassurance to those who worry about descriptions of endplate changes such as Schmorl's nodes.

The other finding of note in this SR is the relatively low reported incidence of spondylolysis. This may be a result of either the low number of patients included in the studies where this was specifically looked for (small sample size error), or it may be a reflection of the limitations of the diagnostic modalities regarding detection of spondylolysis or spondylolisthesis (remembering that MRIs are most commonly performed supine). It may also invite further critical review of the widely held assumption that spondylolysis or spondylolisthesis are usually asymptomatic in pediatric/adolescents cohorts.

Another point worth considering is the sampling methodology, which may have introduced a selection bias into the systematic review. Differentiating pediatric and adolescent patients into "athletes" and "nonathletes" may be problematic in light of a large percentage of children participating in sports. It would seem helpful to come up with a differentiating definition for athletes and nonathletes in nonadult patient populations and also come up with rates of asymptomatic "athlete" patients who have abnormalities on spinal MRI.

Finally, EBSJ invites its readers to look at the additional Web material provided, which also features a complete listing of excluded studies, which is a comprehensive list of the current state of pediatric and adolescent disc pathology and low back pain. 